\title{
PENGUJIAN OEDOMETER PADA TANAH RESIDUAL VULKANIK TROPIS
}

\author{
Hadi U. Moeno \\ Dosen Tetap, Prodi Teknik Sipil, Universitas Sangga Buana-YPKP Bandung \\ Dosen LB, Jurusan Teknik Sipil, Universitas Kristen Maranatha
}

\begin{abstract}
Test of Oedometer or One Dimensional Consolidation usualy done to get deformation parameter such as compression index $\mathrm{C}_{\mathrm{c}}$, coefficient of consolidation $\mathrm{C}_{\mathrm{v}}$ and pre-consolidation pressure $\mathrm{p}_{\mathrm{c}}$, usualy done to the sedimentary soils. This research done to the tropical residual soils which condition of physical of in field is not saturated then is done testing of oedometer at condition of saturated specimen and not saturated. From result obtained simple visible that there is the relation of strong correlation between values $\mathrm{Cc}$ for $\mathrm{Sr}=1$ and $\mathrm{Cc}$ for $\mathrm{Sr}<1$, with equation of continuity of empirical correlation is $\mathrm{C}_{\mathrm{Sr}_{\mathrm{r}}=1}=1,33\left(\mathrm{C}_{\mathrm{Sr}_{\mathrm{r}} 1}\right)$, and so it is with parameter OCR that is OCR for $\mathrm{Sr}=1$ equal to OCR for $\mathrm{Sr}<1$.
\end{abstract}

Keywords: Oedometer, Cc, OCR.

\begin{abstract}
ABSTRAK
Pengujian oedometer atau konsolidasi ekamatra biasa dilakukan untuk mendapatkan parameter deformasi antara lain indeks pemampatan $\mathrm{C}_{\mathrm{c}}$, koefisien konsolidasi $\mathrm{c}_{\mathrm{v}}$ dan tekanan pra-konsolidasi $\mathrm{p}_{\mathrm{c}}$ yang biasa dilakukan pada tanah sedimen. Penelitian ini dilakukan pada tanah residual tropis padamana kondisi fisik di lapangan tidak jenuh, kemudian dilakukan pengujian oedometer pada kondisi benda uji yang jenuh dan tidak jenuh. Dari hasil yang diperoleh secara sederhana dapat dilihat bahwa terdapat hubungan korelasi yang erat antara nilai $C_{c}$ untuk $S_{r}=1$ dan $C_{c}$ untuk $S_{r}<1$, dengan persamaan korelasi empirik adalah $\mathrm{C}_{\mathrm{Sr}=1}=1.33\left(\mathrm{C}_{\mathrm{Sr}<1}\right)$, demikian juga dengan parameter OCR yaitu OCR untuk $\mathrm{Sr}=1$ sama dengan OCR untuk $\mathrm{Sr}<1$.
\end{abstract}

Kata kunci: Oedometer, $\mathrm{C}_{\mathrm{c}}$, OCR.

\section{PENDAHULUAN}

Pengujian oedometer atau yang lebih luas dikenal sebagai pengujian konsolidasi ekamatra adalah pengujian laboratorium untuk mendapatkan parameter konsolidasi yang akan dipakai sebagai data masukan dalam analisa penurunan fundasi. Pengujian ini biasanya dilakukan terhadap benda uji yang jenuh air sesuai dengan salah satu kriteria konsolidasi dari Terzaghi bahwa teori konsolidasi hanya berlaku untuk tanah lempung yang jenuh air, maka sebelum uji konsolidasi dilakukan, benda uji harus djenuhkan lebih dulu dan ini memerlukan waktu cukup lama belum lagi pengendalian kejenuhan benda uji yang jarang dibuktikan secara hitungan. Untuk itu dilakukan penelitian terhadap sepasang tanah dengan kondisi kejenuhan yang berbeda yaitu benda uji untuk $\mathrm{Sr}=1$ dan benda uji untuk $\mathrm{Sr}<1$. Penelitian dilakukan terhadap tanah residual tropis yang banyak terdapat di Indonesia agar dapat 
dianalisa apakah teori konsolidasi yang didasarkan kepada tanah sedimen masih berlaku untuk tanah residual.

\section{DASAR TEORI}

Teori dasar yang dipakai sama dengan teori awal tentang konsolidasi (Terzaghi) dan prosedur uji sesuai dengan standar uji yang berlaku baik menurut ASTM maupun SNI. Untuk mendapatkan nilai tekanan tanah pra-konsolidasi $\mathrm{p}_{\mathrm{c}}$ tidak digunakan cara Casagrande atau Schmertmann, tapi menggunakan metode Senol yang relatif belum banyak dikenal dan dipakai dalam menghitung $\mathrm{p}_{\mathrm{c}}$ dari hasil uji konsolidasi. Secara logis teori konsolidasi yang dikenal selama ini didasarkan kepada hasil penelitian terhadap tanah sedimen, sehingga layak untuk dipelajari apakah masih dapat diberlakukan terhadap tanah residual.

\section{METODOLOGI}

Metode penelitian yang digunakan adalah metode eksperimen di laboratorium, yaitu melakukan serangkaian pengujian konsolidasi (oedometer) di laboratorium terhadap benda uji yang dibuat dari contoh uji asli (undisturbed samples), dimana contoh uji diambil dari lubang bor inti setiap kedalaman $2.00 \mathrm{~m}$ dari 2 titik bor inti yang masing-masing dengan kedalaman pemboran maksimum 20 m, sehingga keseluruhan diperoleh 20 contoh tanah asli. Dari setiap tabung contoh asli dibuat sepasang benda uji; satu benda uji dijenuhkan $(\mathrm{Sr}=1)$ dan lainnya langsung di uji $(\mathrm{Sr}<1)$. Lokasi pemboran di Resor Dago Pakar Bandung dengan ketebalan tanah residual cukup tebal lebih dari $30 \mathrm{~m}$. Selain nilai $\mathrm{C}_{\mathrm{c}}$ dilakukan pula perhitungan untuk mendapatkan nilai $\mathrm{p}_{\mathrm{c}}$ atau untuk tanah residual lebih dikenal sebagai yield pressure $\mathrm{p}_{\mathrm{y} \text {-oed }}$ yang nilai ini dipakai untuk menghitung OCR. Juga dihitung nilai modulus elastisitas $\mathrm{E}_{\text {oed }}$ untuk kedua kondisi derajat kejenuhan.

\section{TANAH RESIDUAL TROPIS}

Mekanika tanah, yang pada zaman ini merupakan bagian penting dari ilmu teknik sipil, berkembang dinegeri Eropah dan Amerika Utara. Pengertian akan sifat-sifat tanah (terutama tanah yang berbutir halus seperti lempung) berdasarkan pada pengujian dan penelitian jenis tanah yang disebut tanah endapan (sedimentary soils). Sebagian besar jenis tanah yang terdapat di Eropah dan Amerika Utara termasuk golongan tanah dari jenis endapan ini. Hampir setiap buku tentang mekanika tanah ditulis seolah-olah tidak ada tanah selain tanah endapan. Buku mekanika tanah juga membagi tanah endapan dalam dua macam, yaitu yang “normally consolidated” dan yang “over consolidated”. Dapat dikatakan bahwa 
dasar empirik atau dasar teoritis dari mekanika tanah berdasarkan hampir seratus persen pada penilaian dan penelitian tanah endapan. Buku mekanika tanah jarang mengakui adanya tanah “residual” (residual soil)(Wesley L.D., 1973, 2001).

Sifat-sifat tanah residual sering agak berbeda dengan sifat-sifat tanah endapan, dan teori-teori atau pengertian yang berlaku pada tanah endapan tidak dengan sendirinya dapat dipakai pada tanah (Wesley, 1973, 1978, 2001).

Pada tanah endapan, mineral-mineral yang terpenting adalah kaolinite, illite dan motmorillonite, dan pengaruhnya pada sifat-sifat tanah sudah lama diketahui dan diterapkan dalam buku mekanika tanah. Mineral-minreal tersebut juga terdapat pada sejumah jenis tanah residual. Akan tetapi selain itu didalam tanah residual terdapat pula beberapa jenis mineral yang tidak terdapat pada tanah endapan. Mineral-mineral yang besar pengaruhnya terhadap sifat tanah residual adalah antara lain Halloysite, Allophane dan Sesquioxides

\section{HASIL PENELITIAN}

Pengujian konsolidasi dilaksanakan terhadap contoh tanah UNDS sebanyak 20 pengujian dari 20 Unds. Pengujian dibagi menjadi 2 bagian utama, yaitu contoh tanah diuji pada keadaan jenuh $(\mathrm{Sr}=1)$ dan contoh tanah dalam keadaan asli tidak jenuh ( $\mathrm{Sr}<1)$, hal ini dilakukan untuk melihat kemungkinan hubungan yang ada diantaranya. Hasil pengujian secara lengkap terdapat pada lampiran hasil pengujian contoh tanah Unds, dan ringkasannya seperti pada Tabel 1. Karena pengujian dilakukan pada 2 (dua) kondisi derajat kejenuhan, maka hasil yang diperoleh adalah pasangan hasil pengujian dengan kondisi Sr yang berbeda.

Penentuan nilai indeks kompresi $\left(\mathrm{C}_{\mathrm{c}}\right)$ dilakukan secara konvensional, sedangkan nilai tekanan pra-konsolidasi yang pada tanah residual diprediksikan sebagai tekanan leleh (yield pressure $=\mathrm{p}_{\mathrm{y}}=\mathrm{p}$ 'c oed), ditentukan secara grafis dengan mempergunakan metode Senol (1997) yaitu Strain Enegry - log pressure method. Metode ini memberikan hasil yang hampir sama dengan cara Casagrande, namun pada pelaksanaannya lebih mudah dan pasti dalam mendapatkan nilai $\mathrm{p}_{y}$. Gambar 1. adalah profil OCR terhadap kedalaman untuk lokasi Graha Permai dan Graha Kusuma.

Dari Gambar 1 terlihat bahwa profil OCR untuk $\mathrm{Sr}=1$ dan $\mathrm{Sr}<1$, berimpit satu dengan lainnya, dengan demikian nilai OCR untuk $\mathrm{Sr}=1$ tidak berbeda dengan nilai OCR untuk $\mathrm{Sr}<1$, atau nilai OCR dapat ditentukan dengan pengujian pada contoh tanah asli pada keadaan $\mathrm{Sr}<1$ tanpa proses penjenuhan terlebih dahulu. 


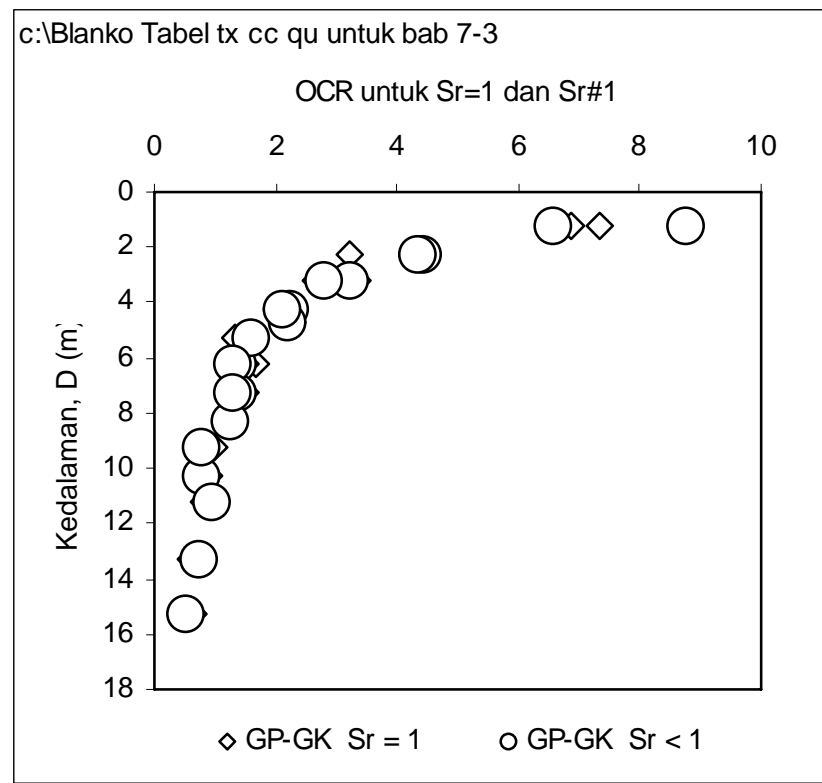

\section{Gambar 1. Profil OCR terhadap kedalaman untuk $\mathrm{Sr}=1$ dan $\mathrm{Sr}<1$, Resor Dago Pakar.}

Tabel 1. Hasil pengujian konsolidasi Eka Matra (Oedometer test)

\begin{tabular}{|c|c|c|c|c|c|c|c|c|}
\hline \multirow{3}{*}{$\begin{array}{l}\text { Hole } \\
\text { No. }\end{array}$} & \multirow{2}{*}{ Depth } & \multicolumn{2}{|c|}{ Cc } & \multicolumn{2}{|c|}{ py-oed } & \multicolumn{2}{|c|}{ OCR } & \multirow{2}{*}{ ov } \\
\hline & & $\mathrm{Sr}=1$ & Sr\#1 & $\mathrm{Sr}=1$ & Sr\#1 & $\mathrm{Sr}=1$ & Sr\#1 & \\
\hline & $\mathrm{m}$ & - & - & $\mathrm{kg} / \mathrm{cm} 2$ & $\mathrm{~kg} / \mathrm{cm} 2$ & - & - & $\mathrm{kg} / \mathrm{cm} 2$ \\
\hline \multirow{9}{*}{ BH-1 } & $1.0-1.50$ & 0.33 & 0.18 & 1.37 & 1.75 & 6.85 & 8.75 & 0.20 \\
\hline & $2.00-2.50$ & 0.55 & 0.18 & 1.13 & 1.55 & 3.23 & 4.43 & 0.35 \\
\hline & $3.00-3.50$ & 0.56 & 0.25 & 1.70 & 1.65 & 3.33 & 3.24 & 0.51 \\
\hline & $4.00-4.50$ & 0.21 & 0.14 & 1.37 & 1.50 & 2.04 & 2.24 & 0.67 \\
\hline & $4.50-5.00$ & 0.36 & 0.30 & 1.70 & 1.65 & 2.27 & 2.20 & 0.75 \\
\hline & $6.00-6.50$ & 0.25 & 0.12 & 1.67 & 1.37 & 1.69 & 1.38 & 0.99 \\
\hline & $7.00-7.50$ & 0.21 & 0.19 & 1.73 & 1.59 & 1.52 & 1.39 & 1.14 \\
\hline & $8.00-8.50$ & 0.43 & 0.32 & 1.67 & 1.60 & 1.28 & 1.23 & 1.30 \\
\hline & $10.00-10.50$ & 0.26 & 0.14 & 1.44 & 1.24 & 0.89 & 0.77 & 1.62 \\
\hline \multirow{11}{*}{ BH-2 } & $1.0-1.50$ & 0.12 & 0.10 & 1.54 & 1.38 & 7.33 & 6.57 & 0.21 \\
\hline & $2.00-2.50$ & 0.41 & 0.20 & 1.58 & 1.60 & 4.27 & 4.32 & 0.37 \\
\hline & $3.00-3.50$ & 0.29 & 0.16 & 1.44 & 1.50 & 2.67 & 2.78 & 0.54 \\
\hline & $4.00-4.50$ & 0.20 & 0.17 & 1.40 & 1.46 & 2.00 & 2.09 & 0.70 \\
\hline & $5.00-5.50$ & 0.21 & 0.12 & 1.16 & 1.37 & 1.33 & 1.57 & 0.87 \\
\hline & $6.00-6.50$ & 0.26 & 0.21 & 1.53 & 1.34 & 1.49 & 1.30 & 1.03 \\
\hline & $7.00-7.50$ & 0.26 & 0.12 & 1.48 & 1.55 & 1.23 & 1.29 & 1.20 \\
\hline & $9.00-9.50$ & 0.49 & 0.37 & 1.53 & 1.21 & 1.00 & 0.79 & 1.53 \\
\hline & $11.00-11.50$ & 0.25 & 0.22 & 1.50 & 1.72 & 0.81 & 0.92 & 1.86 \\
\hline & $\mid 13.00-13.50$ & 0.36 & 0.15 & 1.31 & 1.55 & 0.61 & 0.72 & 2.14 \\
\hline & $15.00-15.05$ & 0.41 & 0.37 & 1.58 & 1.32 & 0.63 & 0.52 & 2.52 \\
\hline
\end{tabular}


Gambar 2 adalah hubungan nilai indeks kompresi $\left(\mathrm{C}_{\mathrm{c}}\right)$ untuk $\mathrm{Sr}=1$ dan $\mathrm{Sr}<1(\mathrm{Sr} \#$ 1). Dari hubungan tersebut dapat diperoleh persamaan korelasi empiris sebagai berikut:

$$
\mathrm{C}_{\mathrm{cSr}=1}=1.33\left(\mathrm{C}_{\mathrm{cSr}<1}\right)
$$

Diperoleh nilai $\mathrm{C}_{\mathrm{c}}$ untuk $\mathrm{Sr}=1$, adalah 1.33 lebih besar daripada nilai $\mathrm{C}_{\mathrm{c}}$ untuk $\mathrm{Sr}<$ 1, dengan demikian nilai Cc dapat diperoleh dari hasil pengujian konsolidasi eka matra pada contoh tanah dengan $\mathrm{Sr}<1$. (contoh tanah uji tidak perlu melalui proses penjenuhan terlebih dahulu).

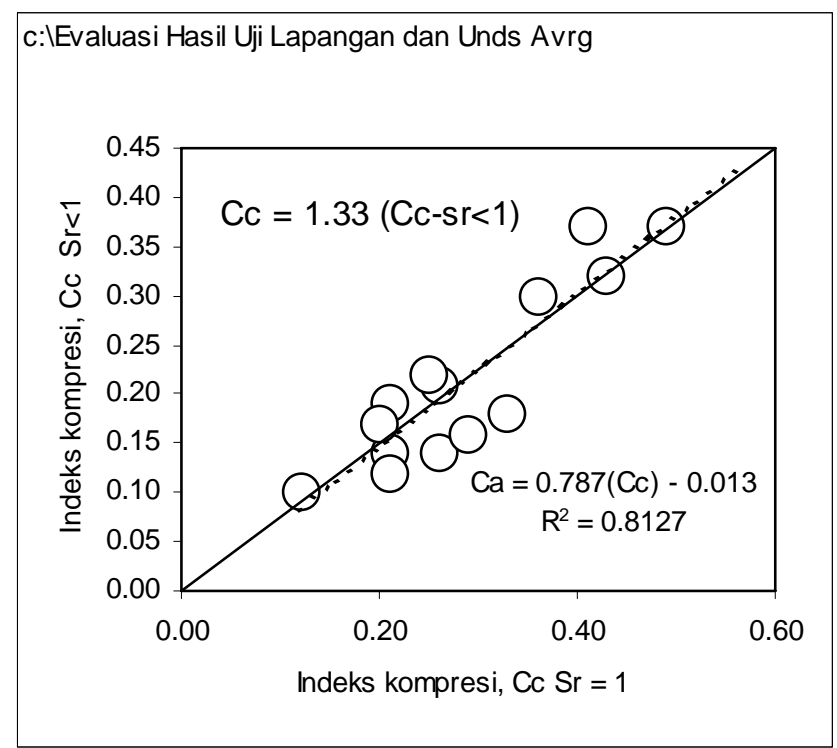

\section{Gambar 2. Hubungan antara $\mathrm{C}_{\mathrm{c}}$ dengan $\mathrm{Sr}=1$ dan $\mathrm{C}_{\mathrm{c}}$ dengan $\mathrm{Sr}<1$, lokasi Resor Dago Pakar.}

Gambar 3 adalah hubungan antara nilai $\mathrm{p}_{\mathrm{y} \text {-oed }}$ untuk $\mathrm{Sr}=1$ dengan $\mathrm{p}_{\mathrm{y}}$ untuk $\mathrm{Sr}<1$, dengan $\mathrm{p}_{\mathrm{y}-\mathrm{oed}}$ yang dimaksud adalah yield pressure atau $\mathrm{p}_{\mathrm{c}}$ (pre-consolidation pressure) pada tanah sedimen. Terlihat bahwa data yang diperoleh menunjukan satu kelompok yang saling berdekatan, dan untuk mendapatkan persamaan korelasi empiris yang mungkin ada ialah dengan membuat grafik hubungan antara rasio $\left(\mathrm{p}_{\mathrm{y}} \mathrm{Sr}<1\right) /\left(\mathrm{p}_{\mathrm{y}} \mathrm{Sr}=1\right)$ dengan nilai $\mathrm{py} \mathrm{Sr}<$ 1 seperti pada Gambar 4. Hasil yang diperoleh ialah:

$$
\left(\mathrm{p}_{\mathrm{ySr}<1} / \mathrm{p}_{\mathrm{ySr}=1}\right)=\left(\mathrm{p}_{\mathrm{ySr}<1}\right)-0.5
$$

dengan nilai $\mathrm{p}_{\mathrm{y}} \mathrm{Sr}<1$ yang diketahui, dengan Gambar 4. dapat diketahui $\mathrm{p}_{\mathrm{y} \text {-oed }}$. 


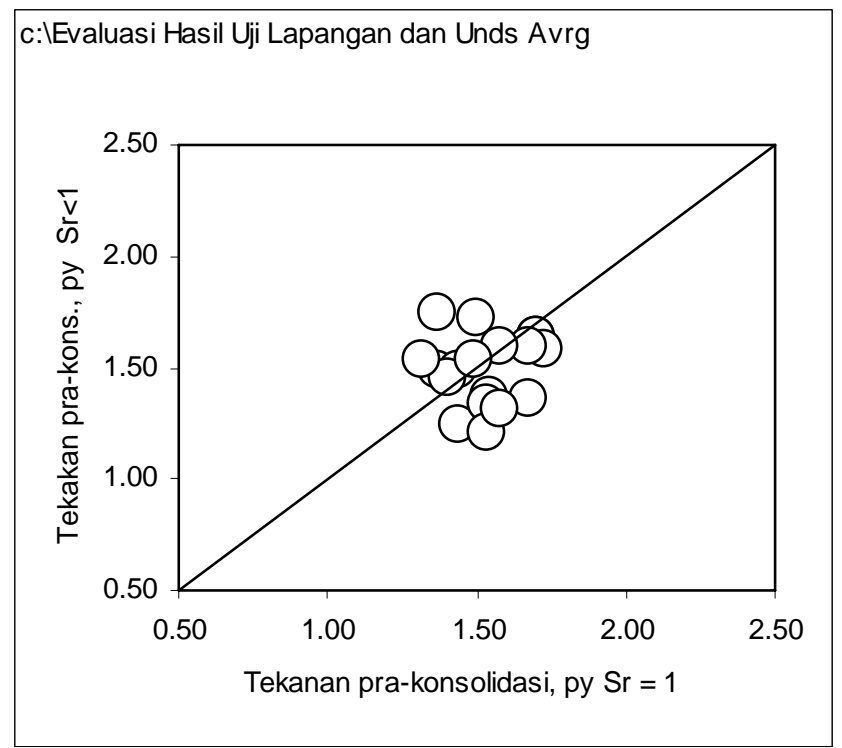

Gambar 3. Hubungan antara $\mathrm{p}_{\mathrm{y}}$ dengan $\mathrm{Sr}=1$ dan $\mathrm{p}_{\mathrm{y}}$ dengan $\mathrm{Sr}<1$, lokasi Resor Dago Pakar.

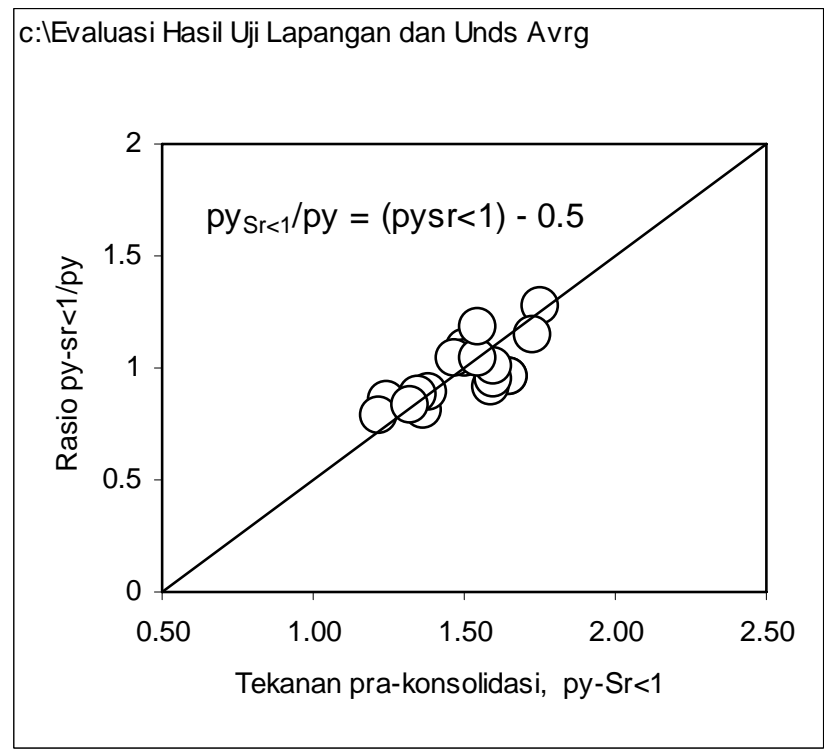

Gambar 4. Hubungan antara $p_{y}$ dengan $\mathrm{Sr}<1$ dan $p_{y S r}<1 / p_{y S r}=1$, lokasi Resor Dago Pakar.

Gambar 5 adalah profil dari nilai modulus elastisitas oedometer ( $E_{\text {oed }}$ ) untuk 2 (dua) kondisi, yaitu $\mathrm{E}$ untuk kondisi $\mathrm{Sr}<1$ dan $\mathrm{E}_{\text {oed }}$ untuk $\mathrm{Sr}=1$. Dari profil tersebut terlihat bahwa $\mathrm{E}_{\text {oed }}$ mempunyai nilai yang lebih kecil dibandingkan dengan $\mathrm{E}$ dengan $\mathrm{Sr}<1$. 
Untuk mendapatkan hubungan empiris diantara kedua data E tersebut dibuat grafik hubungan antara rasio $\left(\mathrm{E} / \mathrm{E}_{\text {oed }}\right)$ dengan $\mathrm{E}(\mathrm{Sr}<1)$, disajikan pada Gambar 6. Data yang dipakai adalah sama dengan data untuk membuat profil $\mathrm{E}$ dan $\mathrm{E}_{\text {oed }}$.

Dari perhitungan secara regresi diperoleh persamaan korelasi empiris sebagai berikut:

$$
\mathrm{Y}=0.0207 \mathrm{X}+0.2308 ; \mathrm{R}^{2}=0.8117
$$

dengan : $\mathrm{Y}: \mathrm{E}_{\mathrm{Sr}<1} / \mathrm{E}_{\mathrm{oed}}$

$$
\mathrm{X}: \mathrm{E}_{\mathrm{Sr}<1}
$$

Sehingga persamaan diatas dapat ditulis dengan lengkap sebagai berikut :

$$
\begin{aligned}
& \left(E_{S r<1} / E_{o e d}\right)=0.0207\left(E_{S r<1}\right)+0.2308 \\
& \left(E_{\text {oed }}\right)=E_{S r<1} /\left(0.0207\left(E_{S r<1}\right)+0.2308\right)
\end{aligned}
$$

dengan demikian nilai $\mathrm{E}_{\text {oed }}$ dapat ditentukan dari hasil pengujian konsolidasi pada kondisi $\mathrm{Sr}$ $<1$, kemudian gunakan grafik pada Gambar 6. untuk mendapatkan nilai rasio ( $\left.\mathrm{E}_{\mathrm{Sr}<1} / \mathrm{E}_{\mathrm{oed}}\right)$, dan selanjutnya nilai $E_{\text {oed }}$ dapat dihitung melalui nilai $E_{S r<1}$ yang telah diketahui sebelumnya, atau dengan mempergunakan persamaan diatas melalu nilai $\mathrm{E}_{\mathrm{Sr}<1}$ yang diketahui dari hasil pengujian konsolidasi pada derajat kejenuhan $\mathrm{Sr}<1$.

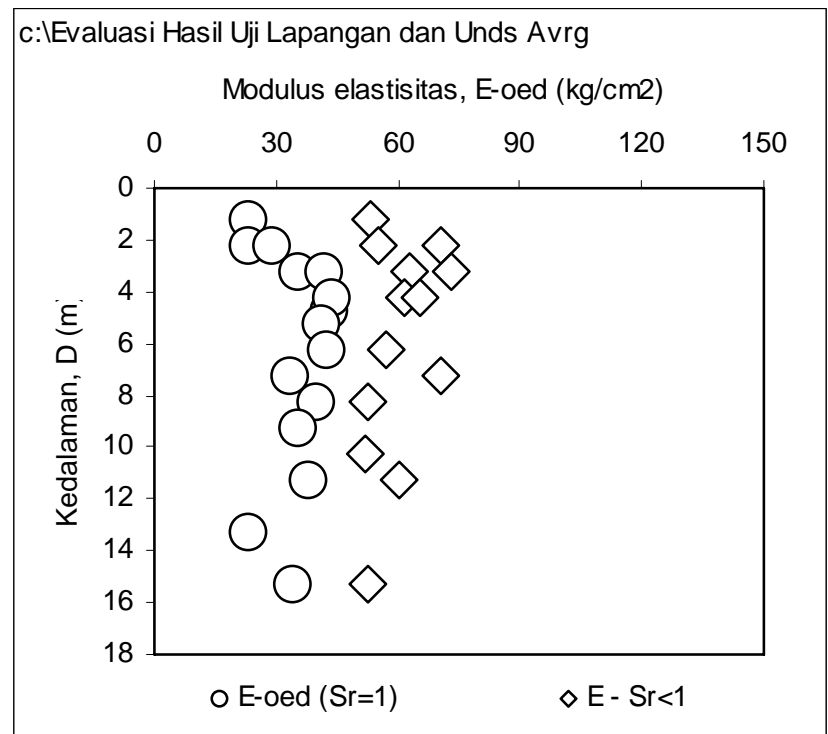

Gambar 5. Profil nilai modulus elastisitas hasil pengujian kosolidasi $\mathrm{Sr}<1$ dan $\mathrm{Sr}=1$. 


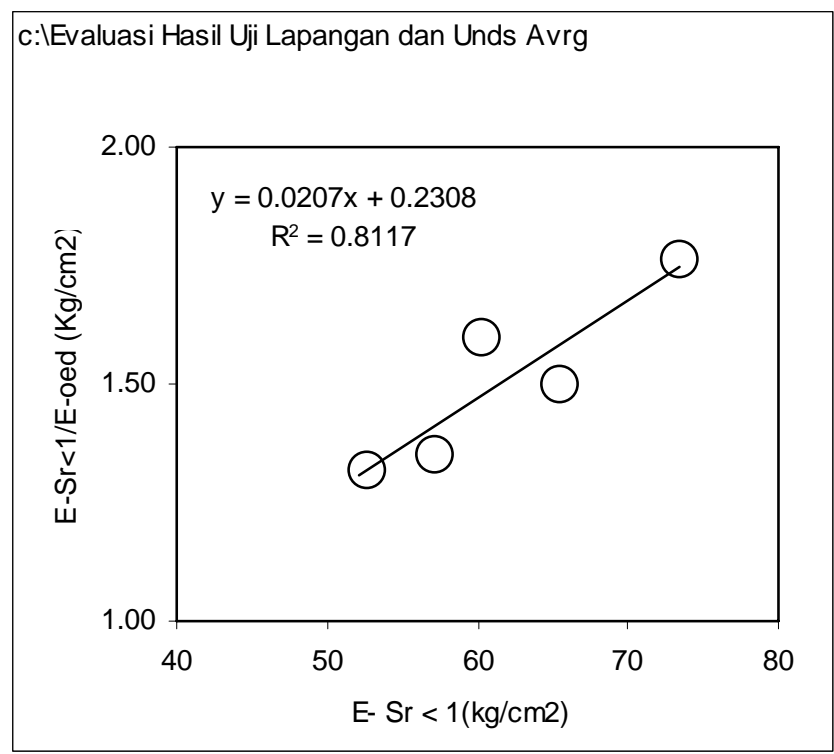

Gambar 6. Hubungan antara $\left(E_{S r<1} / E_{\text {oed }}\right)$ dan $E_{S r<1}$ hasil pengujian kosolidasi $\mathrm{Sr}<1$ dan $\mathrm{Sr}=1$, lokasi Resor Dago Pakar.

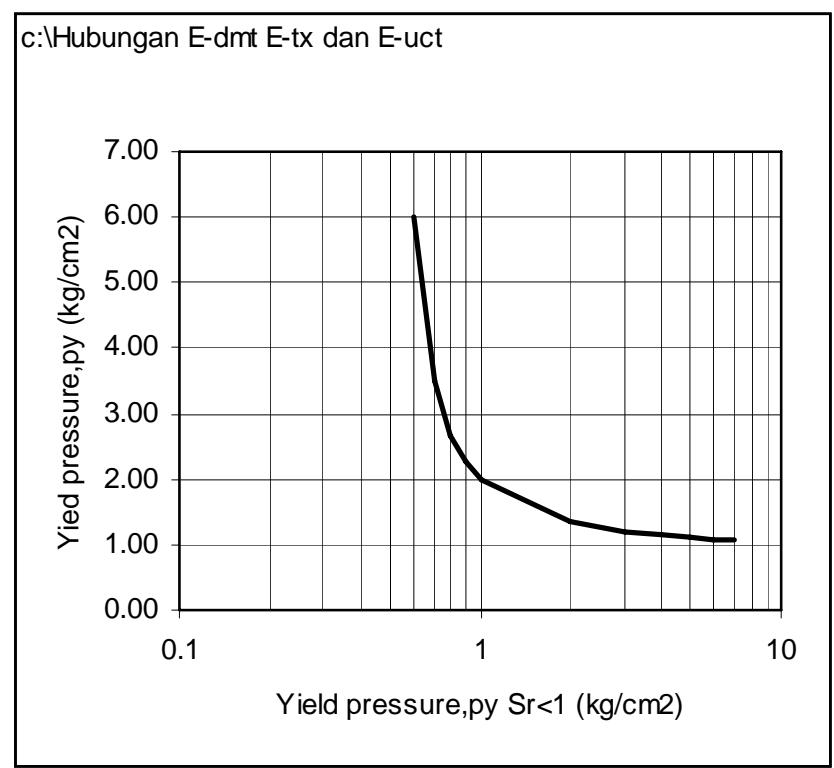

Gambar 7. Hubungan antara $p_{y-S r<1}$ dan $p_{y-o e d}$ (yield pressure), lokasi Resor Dago Pakar. 


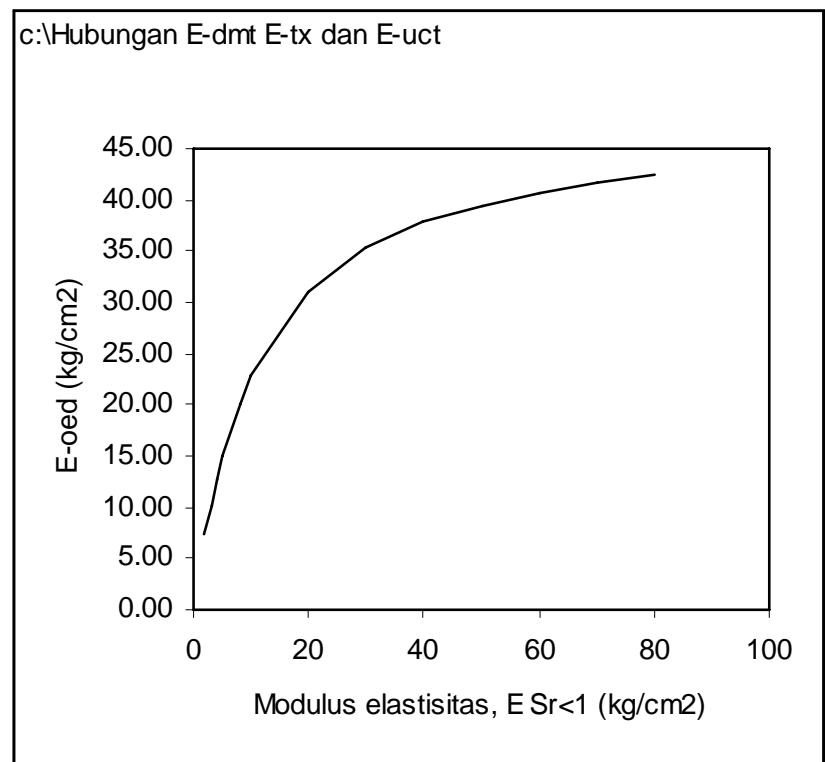

Gambar 8. Hubungan antara $E_{S r<1}$ dan $E_{\text {oed }}$ lokasi Resor Dago Pakar.

\section{KESIMPULAN}

Kesimpulan yang diperoleh bahwa dengan data yang minim pada penelitian ini dapat diperoleh persamaan korelasi empirik antara kondisi tanah jenuh air dan tidak jenuh air dalam nilai parameter hasil uji oedometer (konsolidasi ekamatra), $\mathrm{C}_{\mathrm{c}}, \mathrm{P}_{\mathrm{y} \text {-oed, }}$ OCR dan $\mathrm{E}_{\text {oed }}$.

Dibutuhkan kajian lebih dalam untuk menambah data hasil uji oedometer pada tanah residual sehingga diperoleh hasil yang lebih komprehensif yang berlaku umum.

\section{DAFTAR PUSTAKA}

1. Singh, A., Chowdhary, G.R. (1992), Soil Engineering in Theory and Practice, Second Edition Geotechnical Testing and Instrumentation, Cicil Engineering Dept. University of Jodhpur, Jodhpur, CBS Publishers \& Distributors Pvt. Ltd.

2. ASTM (1990), Manual of Soil Laboratory Testing Vol.2 (ASTM D), Test Mesthod for One Dimensional Consolidation Properties of Soils, ASTM D 2435-90, Annual Book of ASTM Standard vol. 2.

3. Das B.M. (1987), Advanced Soil Mechanics, Hemisphere Publishing Corporation, New York.

4. Head, K.H., Manual of Soil Laboratory Testing, Pentech Press London; Plymouth.

5. Hunt, R.E. (1984), Geotechnical Engineering Investigation Manual, McGraw-Hill Book Company, Series in Geotechnical Engineering. 
6. Hayes, J.A. (1990), The Marchetti Dilatometer and Compressibility, Paper Presented to the Southern Ontario Section of the Canada Geotechnical Society, Seminar on “In-Situ Testing and Monitoring, September 1990.

7. Lambe, T.W., Whitman R.V. (1969), Soil Mechanics, Wiley Eastern Limited, New Delhi.

8. Schmertmann, J.H. (1953), The Undisturbed Consolidation Behaviour of Clay Soils, First Int. Conf. On Geomechanics in Tropical Lateritic and Saprolitic Soils, Brazil, $1-33$.

9. Senol A. (1997), Determination of Pre-consolidation Pressure, The Institute of Science and Technology, Turkey, Phd Thesis.

10. Senol A., Saglamer A. (1996), Determination of Pre-consolidation Pressure, The British Geotechnical Scociety’s Young Geotechnical Engineer's Symposium, Oxford University.

11. Wesley L.D. (1999), Geotechnical Engineering in Residual Soil, Paper KOGEI-8, 1999, Indonesia-HATTI. 